\title{
Thoracic endovascular aortic repair for ascending aortic aneurysm or dissection
}

\author{
Derek Serna-Gallegos ${ }^{1}$, Edgar Aranda-Michel ${ }^{2}$, Forozan Navid ${ }^{1}$, Ibrahim Sultan ${ }^{1,2}$ \\ ${ }^{1}$ Heart and Vascular Institute of the University of Pittsburgh Medical Center, Pittsburgh, PA, USA; ${ }^{2}$ Department of Cardiothoracic Surgery, School \\ of Medicine, University of Pittsburgh, Pittsburgh, PA, USA \\ Correspondence to: Ibrahim Sultan, MD. Division of Cardiac Surgery, Department of Cardiothoracic Surgery, University of Pittsburgh; Center for \\ Thoracic Aortic Disease, Heart and Vascular Institute, University of Pittsburgh Medical Center, 5200 Centre Ave, Suite 715, Pittsburgh, PA 15232, \\ USA. Email: sultani@upmc.edu.
}

Submitted Jun 14, 2021. Accepted for publication Oct 19, 2021.

doi: 10.21037/acs-2021-taes-20

View this article at: https://dx.doi.org/10.21037/acs-2021-taes-20

\section{Clinical vignette}

A 67-year-old year woman with heart failure, chronic obstructive pulmonary disease (COPD), diabetes, chronic kidney disease with a failed renal transplant on hemodialysis, was transferred to our institution with an acute Type A aortic dissection (TAAD). Several months prior to her presentation, she suffered a COPD exacerbation requiring a tracheostomy and while recovering, experienced altered mental status. Imaging demonstrated a stroke as well as an acute TAAD. The dissection flap was isolated to the ascending aorta above the origins of uninvolved coronary arteries and below the innominate artery with an aneurysm measuring $4.7 \mathrm{~cm}$. The patient was deemed of prohibitive risk for open repair. Ascending thoracic endovascular aortic repair (TEVAR) performed off label was discussed with the patient's family and they were agreeable to proceed.

\section{Surgical technique}

\section{Preparation and exposition}

The procedure is performed in the supine position under general anesthesia in a hybrid operating room. Central, venous and arterial catheters are utilized. Chest, groins and legs are prepped and draped in a standard fashion. A right radial arterial sheath and pigtail are utilized for aortography. Electroencephalogram (EEG) and somatosensory evoked potentials (SSEP) are utilized. We always utilize a temporary pacemaker when deploying the stent graft. We perform a common femoral artery cutdown for access. The patient is systemically heparinized to an activated clotting time (ACT) greater than 300. A J-wire (Angiodynamics, New York, USA) and a JR catheter (Boston Scientific, Massachusetts, USA) are utilized to navigate gain access to the ascending aorta. Intravascular ultrasound (IVUS) is utilized in all patients with an aortic dissection.

\section{Operation}

Aortography and identification of the coronary ostia is performed using the marker pigtail. Using gated 3D computerized tomography (CT) scans, the proximal and distal landing zones were carefully studied and measured at orthogonal angles to the long axis. A $2 \mathrm{~cm}$ landing zone is ideal but often not possible in the ascending aorta. The aortic valve can be crossed using an AL1 catheter (Boston Scientific, Massachusetts, USA) and an extra-stiff double curved Lunderquist wire (Cook, Indiana, USA) is placed in the left ventricle.

The endograft is then advanced through the iliofemoral system across the aortic arch and is positioned just above the sinotubular junction. It is important not to cross the sinotubular junction so as not to affect the aortic valve apparatus or compromise any high coronary ostia. Transesophageal echocardiography can also be utilized when fluoroscopic imaging is not sufficient. In this case a $43 \mathrm{~mm} \times 55 \mathrm{~mm}$ standard endograft (Medtronic, Minnesota, USA) was used. Rapid pacing at 180 beats per minute (BPM) was performed while deploying the graft. Subsequent aortography indicated a potential residual tear. A second 
standard endograft, size $46 \mathrm{~mm} \times 55 \mathrm{~mm}$ (Medtronic, Minnesota, USA) was then utilized to seal the residual tear and was deployed in an overlapping fashion. Rapid pacing is important as any cardiac output can cause significant movement of the endograft.

\section{Completion}

After deployment, repeat IVUS and aortography was utilized to evaluate the patency of the coronary arteries and brachiocephalic vessels, as well as stent graft infolding. Infolding is managed with a large trilobed balloon only in overlapping endograft segments to minimize the possibility of rupture. Aortography confirms positioning of the stent graft and evaluates for endoleak. Endoleaks in the ascending aorta in patients with acute aortic dissection are of limited importance, as long as the primary tear is covered. All hardware is removed, and the common femoral artery is repaired.

\section{Comments}

\section{Clinical results}

Several high-volume institutions have begun to explore the option of endovascular therapy for ascending aortic pathology due to the poor outcomes of medical management. Open surgical repair remains standard therapy but in patients with prohibitive risk, endovascular options potentially provide an advantage over medical management. A review of published cases performed between 2000 and 2017 identified 118 patients who underwent endovascular aortic repair for various ascending aortic pathologies (TAAD $50 \%$, pseudoaneurysm $30 \%$, aneurysm $5 \%$, PAU $4 \%$, acute rupture $2 \%$ ). Outcomes demonstrated type 1 endoleak present in $18.6 \%$ of patients, $9.3 \%$ requiring reintervention, all-cause mortality was $15.2 \%$, with aorta-related mortality of $5 \%$ and $3.4 \%$ cerebrovascular complications, with an average follow-up of 17.2 months (1). Other single institution series have demonstrated similar results. Roselli and others reported on thirty-nine patients undergoing ascending aortic TEVAR for various pathologies and demonstrated thirty-day, one-year and five-year overall survival of $81 \%, 74 \%$ and $64 \%$, respectively; with rates of freedom from reintervention at those time periods of $85 \%$, $77 \%$ and $68 \%$, respectively (2). The group at the University of Maryland reported on thirteen patients undergoing ascending TEVAR with operative mortality and stroke of
$15 \%$ and $8 \%$, respectively, with $70 \%$ of patients having no evidence of endoleak (3). Similarly, the group at Baylor College of Medicine demonstrated $66 \%$ overall survival after a median follow-up of 14.4 months, with no aortic related deaths (4).

\section{Advantages}

The advantage of TEVAR in the ascending aorta is based entirely on patient selection. Patients who truly are of prohibitive risk may be better served with ascending TEVAR given historical rates of mortality of $58 \%$ with medical management alone, versus $26 \%$ mortality with open surgical therapy (5). Patient selection hinges open operative risk as well as anatomical constraints.

\section{Disadvantages}

The lack of commercially available endografts designed specifically for the ascending aorta is a distinct disadvantage of endovascular therapy. Existing grafts do not account for serval important features of the ascending aorta; its motion, its curvature, asymmetric dilation with acute aortic dissection and the proximity of the coronary ostia. Other important considerations include patent coronary artery bypass grafts, aortic valve prosthesis and the brachiocephalic vessels. Currently, reports include the use of commercial descending thoracic stents, abdominal cuffs and custom made grafts, none of which address the previously mentioned challenges (1).

\section{Caveats}

Patient selection and the anatomy of the pathology remain the most important considerations when evaluating a patient for ascending TEVAR. Discussion of a potential bailout or lack thereof, is imperative prior to undertaking the procedure. It is important to note that open surgical repair remains the gold standard in operable patients.

\section{Acknowledgments}

Funding: None.

\section{Footnote}

Conflicts of Interest: The authors declare no conflicts of interest. 
Open Access Statement: This is an Open Access article distributed in accordance with the Creative Commons Attribution-NonCommercial-NoDerivs 4.0 International License (CC BY-NC-ND 4.0), which permits the noncommercial replication and distribution of the article with the strict proviso that no changes or edits are made and the original work is properly cited (including links to both the formal publication through the relevant DOI and the license). See: https://creativecommons.org/licenses/by-nc-nd/4.0/.

\section{References}

1. Muetterties CE, Menon R, Wheatley GH 3rd. A systematic review of primary endovascular repair of the

Cite this article as: Serna-Gallegos D, Aranda-Michel E, Navid F, Sultan I. Thoracic endovascular aortic repair for ascending aortic aneurysm or dissection. Ann Cardiothorac Surg 2022;11(1):59-61. doi: 10.21037/acs-2021-taes-20 ascending aorta. J Vasc Surg 2018;67:332-42.

2. Roselli EE, Idrees JJ, Johnston DR, et al. Zone zero thoracic endovascular aortic repair: A proposed modification to the classification of landing zones. J Thorac Cardiovasc Surg 2018;155:1381-9.

3. Ghoreishi M, Shah A, Jeudy J, et al. Endovascular Repair of Ascending Aortic Disease in High-Risk Patients Yields Favorable Outcome. Ann Thorac Surg 2020;109:678-85.

4. Preventza O, Henry MJ, Cheong BY, et al. Endovascular repair of the ascending aorta: when and how to implement the current technology. Ann Thorac Surg 2014;97:1555-60.

5. Hagan PG, Nienaber CA, Isselbacher EM, et al. The International Registry of Acute Aortic Dissection (IRAD): new insights into an old disease. JAMA 2000;283:897-903. 